\title{
PEMINDAHAN MAKAM SEBAB PERBEDAAN PANDANGAN POLITIK
}

\author{
Idrus $\mathbf{L}^{1}$ \\ Mahasiswa Pascasarjana Program Doktor \\ Universitas Islam Negeri Alauddin Makassar \\ Jl. Sultan Alauddin, Somba Opu, Gowa, Indonesia \\ Email: ${ }^{1}$ idrus.latif@yahoo.co.id
}

\begin{abstract}
Basically, dismantling the unlawful grave as long as the bones of the corpse allegedly still in it. But there are some views of the scholars who allow the dismantling of graves if they meet the Shariah law'. It is forbidden to move a corpse without any element of benefit, both for the corpse itself and for the living, otherwise it is permissible to move the corpse if there is an element of benefit, both for the corpse and for the living. Demolition and removal of graves cannot be justified because of differences in political views between landowners or endowments and grave experts because it is not an emergency reason that requires demolition and removal of graves. The context of an emergency that allows the dismantling and removal of graves is condemning human benefit that can not be avoided.
\end{abstract}

Keywords: Graveyard Transfer, Political Views.

\begin{abstract}
Abstrak
Pada dasarnya, membongkar kuburan haram hukumnya selama tulang mayatnya diduga masih ada di dalamnya. Namun ada beberapa pandangan para ulama yang membolehkan dilakukannya pembongkaran kuburan jika memenuhi hukum Syara'. Haram hukumnya memindahkan mayat tanpa ada unsur kemaslahatan, baik untuk mayat itu sendiri maupun orang hidup sebaliknya dibolehkan memindahkan mayat bila terdapat unsur maslahat, baik bagi mayat maupun bagi orang hidup. Pembongkaran dan pemindahan makam tidak bisa dibenarkan hanya karena alasan perbedaan pandangan politik antara pemilik tanah atau pewakaf dan ahli kubur karena bukan alasan darurat yang mengharuskan pembongkaran dan pemindahan makam. Konteks darurat yang membolehkan pembongkaran dan pemindahan makam adalah mengecam kemaslahatan manusia yang tidak bisa dihindari.
\end{abstract}

Kata Kunci: Pemindahan Makam, Pandangan Politik. 


\section{PENDAHULUAN}

Pembongkaran dan pemindahan makam tidak bisa dibenarkan hanya karena alasan perbedaan pandangan politik. Pembongkaran dan pemindahan makam hanya dapat dilakukan dalam situasi darurat. Hal itu senada dengan gijelaskan oleh Abdurrahman Al-Jaziri bahwa وكلك يحرم نقله بعد دفنه إلا لضورة yang artinya; diharam memindahkan jenazah setelah dimakamkan kecuali dalam situasi darurat. ${ }^{1}$

Imam Al-Mawardi dalam kitabnya bahwa sebidang tanah makam yang sudah ditempati merupakan hak jenazah yang mengisi di dalamnya. Oleh karena itu, meski pemilik tanah awalnya hanya meminjamkan sebidang tanah untuk pemakaman, hak penempatan atas tanah tersebut menjadi milik jenazah yang menempati sebidang tanah tersebut. ${ }^{2}$

Masih hangat ditelinga penulis terkait adanya pemindahan kuburan dua warga Desa Toto Selatan, Kecamatan Kabila, Kabupaten Bone Bolango karena beda pandangan politik. Dua makam ini menjadi heboh di media massa karena baru dibongkar oleh Sarce Pomontolo dan keluarganya untuk dipindahkan dari kubur lamanya karena diduga berselisih paham terkait pilihan calon legislatif.

Dua kuburan di Gorontalo harus dipindahkan karena keluarga jenazah berbeda pilihan caleg dengan pemilik tanah yang masih mempunyai hubungan keluarga. Kasus ini membuat heboh pesta demokrasi di Indonesia.

Pemindahan kuburan itu terjadi di Desa Toto Selatan, Kecamatan Kabila, Kabupaten Bone Bolango, Gorontalo. Kuburan yang dipindahkan adalah kuburan almarhum Masri Dunggio, yang sudah dimakamkan 26 tahun lalu dan almarhumah Sitti Aisya Hamzah, yang baru setahun dimakamkan di halaman belakang milik warga bernama Awono.

Abdusalam Polontolo, keluarga pemilik kubur yang dipindahkan tersebut mengatakan pemicunya karena adanya perbedaan pilihan caleg untuk Pemilu

\footnotetext{
${ }^{1}$ Abdurrahman Al-Jaziri, Al-Fiqhu ala Madzhabil Arba'ah (Bairut, Darul Kutub AlIlmiyah, 1994), h. 843.

${ }^{2}$ Al-Mawardi, Al-Hawi Al-Kabir lil Fiqhil Imamis Syafi I (Beirut: Darul Kutub AlIlmiyyah: 1994 M-1414 H.), h. 130.
} 
2019. Keluar ancaman dari pihak keluarga caleg yang akan memindahkan jenazah jika tidak memilih caleg yang juga merupakan pemilik lahan kuburan tersebut.

Pemindahan 2 jenazah yang telah dikebumikan gegara beda pilihan caleg dengan pemilik tanah kuburan sangat mengoyak rasa kemanusiaan. Dari peristiwa itu, penulis menilai tampak jelas terlihat bahwa politik dipahami sebagai sarana mendapatkan kekuasaan sehingga segala macam cara dihalalkan demi memenangkan kontestasi politik.

Kesan penghalalan segala cara dalam meraih kekuasaan politik tidak hanya terjadi dalam perebutan kursi legislatif sebagaimana kasus pemindahan jenazah ke kuburan lain yang terjadi di Gorontalo. Namun juga dalam Pilpres. Politisasi agama, penggunaan fake news dan hoax sebagai mesin elektoral dapat disebut sebagai contohnya. Pemikiran seperti itu menimbulkan pertanyaan bolehkah dilakukan pembongkaran dan pemindahan kuburan karena beda pandangan politik.

\section{PEMBAHASAN}

\section{Epistemologi Kuburan}

a. Terminologi Kuburan

Kata kuburan berasal dari bahasa Arab (qubur) yang telah diIndonesiakan. Kata qubur merupakan bentuk jamak dari kata qabr yang artinya tanah yang digali dengan bentuk dan ukuran tertentu untuk menutupi atau menanamkan jasad. ${ }^{3}$

Terdapat beberapa ayat yang mengatur tentang penguburan mayat, di antaranya dalam QS al-Maidah/5:31.

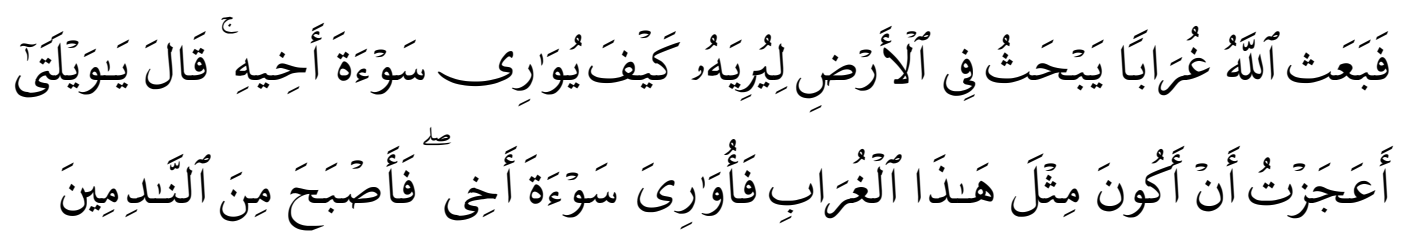

${ }^{3}$ Abdul Aziz Dahlan (et.al), Eksiklopedi Hukum Islam (Cet. I; Jakarta: Ichtiar Baru van Hoeve, 1997), h. 984-985. 
Terjemahnya:

Kemudian Allah menyuruh seekor burung gagak menggali-gali di bumi untuk memperlihatkan kepadanya (Qabil) bagaimana dia seharusnya menguburkan mayat saudaranya. Berkata Qabil: "Aduhai celaka aku, mengapa aku tidak mampu berbuat seperti burung gagak ini, lalu aku dapat menguburkan mayat saudaraku ini?" karena itu jadilah dia seorang di antara orang-orang yang menyesal.

QS Al-Mursalat/77:25-26.

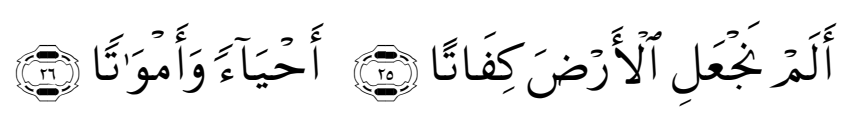

Terjemahnya:

Bukankah Kami menjadikan bumi (tempat) berkumpul orang-orang hidup dan orang-orang mati'?

QS Abasa/80:21.

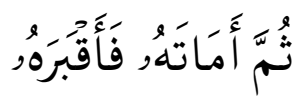

Terjemahnya:

Kemudian Dia mematikannya dan memasukkannya ke dalam kubur.

Nabi Muhammad Saw. memerintah menguburkan jenazah dengan sesegara mungkin sebagaimana yang disampaikannya melalui hadis yang artinya:

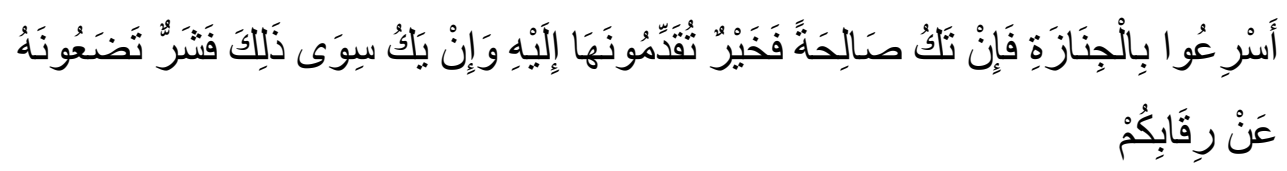

Artinya:

Dari Abu Hurairah r.a dari Nabi Saw. beliau bersabda: Uruslah jenazah itu sesegera mungkin, karena jika ya saleh maka lebih baik kalian serahkan ia kepada kebaikannya dan kalau ia tidak baik, maka tidak baik kalian letakkan kejahatannya di atas pundaknya. (H.R. Muttafaq "Alaih)

Sejumlah ayat dan hadis, para ulama fikih sepakat menyatakan bahwa menguburkan mayat itu hukumnya fardhu kifayah sebagaimana halnya memandikan, mengafani dan menshalatkan ${ }^{5}$

Di antara hikmah dari disyariatkannya penguburan mayat tersebut adalah agar kemuliaan dan kehormatannya sebagai manusia dapat terpelihara dan tidak

${ }^{4}$ Muhammad Ibn Ismail al-Kahlani, Subl al-Salam (Bandung: Dahlan, tt), h. 105.

${ }^{5}$ Ibn Rusyd, Bidayah al-Mujtahid (Beirut: Dar al-Fikr, tt), h. 177. 
menyerupai bangkai binatang, karena Allah Swt. telah menjadikan manusia sebagai makhluk-Nya yang mulia (QS/95:37). Selain itu agar manusia yang hidup tidak merasa terganggu oleh bau yang tidak baik yang timbul dari jasadnya ${ }^{6}$

b. Terminologi Membongkar Kuburan

Ada dua term yang harus dipertegas maknanya, karena antara keduanya memiliki perbedaan. Kedua term tersebut adalah membongkar kuburan dan menggali kuburan. Menggali kuburan, biasanya digunakan kata nabsy al-qubur oleh penulis Arab. Kata ini berarti suatu upaya penggalian kuburan, karena ada sesuatu kepentingan tertentu yang tidak berkaitan dengan mayat yang ada di dalamnya. Ada beberapa motivasi yang dilakukannya penggalian kuburan, antara lain $^{7}$

a) Adanya suatu benda yang berharga jatuh ke dalam kuburan, yaitu ketika seseorang yang membawa benda berharga tersebut ikut menimbun kuburan mayat yang ketika itu pula benda itu jatuh ke dalamnya dengan tidak disadari oleh pemiliknya. Beberapa hari kemudian, pemiliknya menyadari dan menyakini bahwa benda tersebut jatuh ketika ia sedang menimbun kuburan, sedangkan satu-satunya cara untuk mendapatkan benda tersebut kembali adalah dengan menggali kembali kuburan tersebut.

b) Adanya pemasangan pipa saluran air dan instalasi umumnya yang harus melewati kuburan, sehingga harus menggalinya.

c) Pembongkaran dan pemindahan makam hanya dapat dilakukan dalam situasi darurat seperti erosi sungai dan lain sebagainya.

Dalam bahasa Arab yang biasa digunakan untuk pembongkaran kuburan adalah ikhraj al-mayyit min qabrih, yang artinya suatu upaya untuk mengangkat mayat dari lahat kubur, karena ada masalah hukum berkaitan dengan mayat yang harus diselesaikan. ${ }^{8}$ Penggalian kuburan tidak sampai mengangkat dari liang lahatnya, sementara pembongkaran kuburan mengangkat mayat dari liang lahat.

${ }^{6}$ A. Rahman Ritonga dan Zainuddin, Fiqh Ibadah (Cet. I; Jakarta: Gaya Media Pratama, 1997), h. 145.

${ }^{7}$ Mahyuddin, Masailul Fiqhiyyah (Cet. III; Jakata: Kalam Mulia, 1998), h. 149.

${ }^{8}$ Mahyuddin, Masailul Fiqhiyyah, h. 149. 


\section{Hukum Membongkar Makam}

Pada dasarnya membongkar Makam haram hukumnya selama tulang mayatnya diduga masih ada di dalamnya. Namun, menurut Abdul Rahman alJaziri, ada beberapa alasan yang membolehkan pembongkaran kuburan, yaitu ${ }^{9}$ :

a) Mayat tersebut telah dikafani dengan kata kain ghasab sedang pemiliknya tidak mau mengambil ganti rugi.

b) Mayat tersebut telah dikubur di tanah ghasab sedang pemiliknya tidak rela mayat tersebut tetap berada di tanahnya.

c) Mayat tersebut dikuburkan beserta harta dengan sengaja atau pun tidak; baik harta tersebut miliknya atau milik orang lain; banyak ataupun sedikit, sekalipun hanya satu dirham; baik bau mayat tersebut telah berubah atau pun belum. Hukum ini disepakati oleh imam mazhab kecuali Malikiyah.

Menurut ulama Malikiyah, apabila mayat itu beserta harta karena lupa, misalnya jam, cincin atau uang jatuh ketika mayat itu telah dikubur dan telah ditimbun, maka dalam hal ini terdapat dua kemungkinan yaitu harta itu milik mayat sebelum meninggal atau milik orang lain. Bila harta itu milik orang lain, maka kuburnya boleh dibongkar dan harta tadi dikeluarkan, bila bau mayat tersebut belum berubah. Jika baunya telah berubah, maka pemilik harta tersebut harus mau menerima ganti hartanya dari harta peninggalan mayat itu dengan harga yang sama. Hal ini dilakukan bila harta tersebut milik orang lain. Namun bila harta tersebut milik si mayat, maka ahli warisnya harus merelakan harta tersebut, sekalipun cukup berharga, yaitu bila bau mayat tersebut telah berubah. Jika mayat tersebut belum berubah baunya dan harta itu cukup berharga, maka boleh membongkar kuburan tersebut. Demikian pula halnya kuburan itu dapat dibongkar untuk mengeluarkan harta yang diperkirakan belum rusak ${ }^{10}$.

Senada dengan pendapat di atas, menurut Muhammad Jawad Mughniyah, ulama mazhab sepakat menyatakan bahwa pada dasarnya membongkar kuburan haram hukumnya, baik yang meninggal itu mayat anak kecil ataupun orang

\footnotetext{
${ }^{9}$ Abdul Rahman al-jaziri, Fiqh Empat Mazhab, Penerjemah. Chatibul Umam dan Abu Hurairah (Cet. I; Jakarta: Darul Ulum Press, 1996), h. 311.

${ }^{10}$ Abdul Rahman al-jaziri, Fiqh Empat Mazhab, h. 311.
} 
dewasa, orang gila maupun berakal. Namun, dibolehkan membongkar kuburan untuk kemaslahatan mayat, seperti kuburan itu berada di tempat mengalir air, di tepi sungai; dikubur di tempat ghasab baik di tempat musuh maupun bukan, karena tidak tahu maupun karena lupa sedangkan orang yang memilikinya tidak mau menerima ganti rugi; atau dikafani dengan kain yang tidak boleh dipakai untuk kain kafan; atau dikubur bersama dengan harta, baik milik mayat maupun milik orang lain. ${ }^{11}$

Ulama berbeda pendapat tentang kebolehan membongkar kuburan yang mayatnya belum dimandikan atau sudah dimandikan tetapi tidak mengikuti peraturan syarak.

Menurut Imam Syafi'i, jika mayat dikuburkan dan belum dimandikan serta belum dishalatkan, maka dibolehkan untuk membongkar kuburan, lalu memandikan, mengkafani, menshalatkan dan menguburkannya kembali. Hal ini wajib dilakukan sepanjang mayatnya belum rusak. Namun, bila mayat tersebut telah berubah dan berbau busuk, maka tidak dibolehkan membongkarnya ${ }^{12}$. Pendapat ini juga pendapat yang dianut oleh mazhab Maliki, hambali dan mayoritas mazhab Imamiyah ${ }^{13}$. Pendapat ini juga dipegang oleh Imam alSyaukani (w.1250 H/1834 M, ulama fikih dari mazhab Zaidiyah) ${ }^{14}$

Ada beberapa hadis Rasul Saw. yang dijadikan alasan bagi pendapat para ulama di atas yaitu ${ }^{15}$ :

a) Jabir ibn Abdillah menerangkan bahwa Nabi Saw datang kepada Abdullah ibn Ubay setelah Abdullah ibn Ubay dikubur. Kemudian Nabi Saw. mengeluarkan dari kuburnya. Kemudian Nabi Saw. menghembuskan pada

\footnotetext{
${ }^{11}$ Muhammad Jawad Mughniyyah, Fiqh Lima Mazhab, penerjemah team Basrie Press (Cet. I; Jakarta: Basrie Press, 1991), h. 91.

${ }^{12}$ Abi al-Hasan Ali ibn Muhammad ibn Habib al-Mawardi al-Bashri, al-Hawi al-Kabir (Cet. I; Beirut: Dar al-Kutub al-Ilmiyyah, 1994), h. 62.

${ }^{13}$ Muhammad Jawad Mughniyyah, Fiqh Lima Mazhab, h. 91.

${ }^{14}$ Al-Syaukani, Nail al-Authar (Mesir: Musthafa al-Babi al-Halabi, tt), h. 129.

${ }^{15}$ Muhammad Abdullah al-Jardani, Fath al- 'Alam bi Syarh Mursyid al-Anam (Cet. IV; Kairo: al-Salam, 1990), h. 291-292. Lihat juga M. Nashiruddin al-Bani, Menyelenggarakan Jenazah: Antara Sunnah dan Bid'ah, Pent. S. Ziyad Abbas (Jakarta: Pustaka Panji Mas, 1991), h. 142 .
} 
Abdullah ibn Ubay itu air liurnya dan memakaikan kepada Abdullah itu gamisnya (H.R. Bukhari).

Pada riwayat lain dinyatakan bahwa Rasul Saw. datang kepada Abdullah ibn Ubay setelah Abdullah itu dimasukkan kedalam kuburnya. Kemudian Nabi Saw. meminta agar mayat Abdullah dikeluarkan lagi dari kuburnya. Kemudian Nabi meletakkan mayat tersebut di atas kedua lututnya dan menghembuskan air liurnya pada tubuh Abdullah tersebut. Lalu Nabi memakaikan gamisnya pada tubuh Abdullah lalu Nabi berkata "Demi Allah, ketahuilah bahwasanya Abbas juga dikenakan kepadanya gamis". Sufyan berkata "Para sahabat berpendapat bahwasanya Nabi Saw. memakaikan kepada Abdullah baju gamisnya untuk membalas apa yang Abdullah lakukan terhadap Nabi” (H.R. Bukhari ).

b) Jabir r.a. berkata "Rasulullah Saw. memerintahkan supaya pahlawanpahlawan yang gugur dipeperangan Uhud dikembalikan ketempat mereka gugur. Mereka pada saat itu telah dibawa ke kota Madinah".( H.R. Ahmad Abu Daud, al- Turmudzi, al-Nasa"i dan Ibn Majah ).

c) Jabir r.a. berkata: "Telah dikubur bersama ayahku seorang laki-laki, maka hatiku tidak senang hingga aku keluarkan orang itu dan aku kuburkan dalam suatu kuburan tersendiri"(H.R. Bukhari dan an-Nasa"i)

d) Malik ibn Anas dalam kitab al-Muwatta" berkata: "saya mendengar banyak orang berkata bahwasanya Sa'ad ibn Abi Waqqas dan Sa'id ibn Zaid meninggal di al-Aqiq, kemudian keduanya dibawa kekota Madinah dan dikubur di sana.

e) Syuraih ibn Ubay al-Hadhramiy mengatakan bahwasanya ada beberapa orang laki-laki menguburkan sahabat mereka yang belum dimandikan dan mereka tidak memperoleh kain kafan untuknya. Kemudian mereka menemui Muaz ibn Jabai', lalu mereka mengabarkan keadaan itu kemudian mereka diperintahkan Muaz untuk mengeluarkan jenazah itu. Mereka pun lalu mengeluarkan jenazah tersebut dari kuburannya. Kemudian dimandikan dikafankan, diberi obat supaya tubuh jenazah itu dapat bertahan lama, lalu jenazah tersebut dishalatkan dan dikuburkan kembali (H.R. Sa id ibn Mansur). 
f) Para ulama Syafi'iyah berpendapat bahwa haram hukumnya menguburkan orang mati sebelum menyembahyangkannya. Jika dikuburkan sebelum disalati, maka tidak boleh lagi menggali untuk menyembahyangkannya, karena adanya kebolehan salat gaib. Adapun jika dikuburkan tanpa dimandikan pada hal orang itu adalah orang yang wajib dimandikan, maka dalam hal ini ada dua kemungkinan. Pertama, jika dikhawatirkan mayat itu telah berubah dan akan rusak jika kuburannya digali atau dibongkar, maka tidak boleh membongkar kuburannya. Kedua, jika perkirakan belum berubah dan tidak dikhawatirkan mayatnya rusak, maka wajiblah digali, dimandikan, dikafani dan disalati kemudian dikuburkan. ${ }^{16}$.

Bila mayat tersebut dikuburkan tanpa menghadap kiblat, maka menurut mazhab Hanafi dan Maliki tidak perlu melakukan pembongkaran kuburan tersebut. Sedangkan menurut mazhab Syafi'i dan Hambali wajib hukumnya untuk membongkar kuburan tersebut dan menghadapkan mayatnya ke kiblat. ${ }^{17}$

Jika mayat yang berada dalam kuburan tersebut dikafani dengan kain hasil curian, maka dalam hal ini terdapat tiga alternatif penyelesaian, yaitu ${ }^{18}$ :

a) Kuburan tersebut dibongkar untuk meninggalkan kain kafan yang dipakai mayat tersebut diganti dengan kain kafan yang halal.

b) Kuburan tersebut tidak dibongkar, tetapi ahli waris harus mengganti sejumlah uang kepada orang yang kainnya mayat tersebut. Uang yang dijadikan ganti tersebut minimal harus seharga dengan kain yang dipakai mayat tersebut.

c) Jika mayat tersebut telah berubah dan akan menimbulkan aib jika dilakukan pembongkaran kuburan, maka kuburan tersebut tidak boleh dibongkar. Sebaliknya, bila mayat tersebut belum berubah dan tidak ada kekhawatiran akan timbulnya aib, maka dibolehkan membongkar kuburan tersebut. ${ }^{19}$

\footnotetext{
${ }^{16}$ T.M Hasbi ash-Shiddiqy, Koleksi Hadis-hadis Hukum (Cet. V; Jakarta: Yayasan T.M. Hasbi as-Shiddiqy, 1994), h. 293-294.

${ }^{17}$ Al-Jaziri, Fiqh Empat Mazhab, h. 306.

${ }^{18}$ Abi Zakariya Yahya ibn Syaraf al-Nawawi, Raudhah al-Thalibin (Beirut: Dar alKutub al-'ilmiyyah, tt), h. 658. Lihat juga dalam bukunya yang lain seperti al-majmu' Syarh alMahuzzab (Beirut: Dar al-Fikr, 1972), h. 303.

${ }^{19}$ Al-Mawardi, Al-Hawi Al-Kabir lil Fiqhil Imamis Syafi ‘i, h. 233
} 
Jika mayat tersebut dikubur tanpa dikafani, maka dalam hal ini terdapat dua pendapat, yaitu pertama, kuburan tersebut digali dan dikeluarkan jenazahnya sebagaimana digali untuk di mandikan lalu dimandikan. Dan Kedua, kuburan tersebut tidak digalikan.

Ibn Qudamah (w. 620 H/1224 M, ulama Mazhab Hambali) membolehkan dilakukannya pembongkaran kuburan dengan tujuan untuk kemaslahatan. Pembongkaran ini dibolehkan biar diperkirakan mayat tersebut telah hancur menjadi tanah atau minimal tinggal tulang-belulang saja. Bila ragu, maka hendaknya bertanya kepada orang yang ahli dalam bidang tersebut. Bila dalam pembongkaran ditemukan mayat yang masih utuh padahal sebelumnya telah diperkirakan mayat telah hancur, maka hendaknya kuburan tersebut ditimbun kembali seperti sediakala. $^{20}$

\section{Pandangan Ulama Memindahkan Mayat Dan Makam}

Ada dua term yang harus jelas defenisinya pada pembahasan ini, yaitu memindahkan makam dan memindahkan mayat. Term memindahkan makam, yang biasa digunakan kata nagl al-maqabir dalam bahasa Arab, diartikan dengan suatu upaya memindahkan makam dari suatu tempat ke tempat lainnya, karena makam lama tidak dapat lagi berfungsi sebagaimana biasanya, atau ada pertimbangan-pertimbangan lain yang mendesaknya.

Adapun term memindahkan mayat, yang dalam kitab fikih biasa digunakan dengan kata naql al-amwat, diartikan dengan upaya memindahkan mayat-mayat atau tulang-tulangnya, dari suatu daerah ke daerah lainnya, karena telah diwasiatkan oleh mayat ketika masih hidup, atau karena pertimbangan lain.

Memindahkan mayat belum tentu memindahkan makam. Kalau memindahkan mayat berarti makam yang pernah ditempatinya tetap berfungsi sebagaimana biasanya. Sedangkan memindahkan makam bararti bahwa makam yang lama tersebut tidak berfungsi lagi sebagaimana biasanya. Motivasi pemindahan makam dan pemindahan mayat.

\footnotetext{
${ }^{20}$ Ibn Qudamah, al-Mugni 'ala Mukhtasar al-Khurafi (Beirut: Dar al-Kutub al'Ilmiyyah, tt.), h. 34.
} 
1) Motivasi Pemindahan Makam

a. Karena makam yang lama terletak pada areal yang terancam bencana alam. Kalau makam seperti tidak dipindahkan, maka dikhawatirkan nanti ketika terjadi bencana alam, maka tulang-belulang mayat tersebut akan berserakan. Oleh sebab itu, masyarakat setempat berupaya untuk memindahkan areal makam tersebut ke tempat yang lebih aman dari ancaman tersebut.

b. Karena di bawah makam yang lama ditemukan sumber kekayaan alam yang sangat berguna untuk kesejahteraan masyarakat, sehingga pemerintah merencanakan untuk mengeksploitasikan pertambangan di lokasi tersebut, maka makam yang ada di lokasi itu, segera dipindahkan ke lokasi baru.

c. Karena di tempat makam yang lama merupakan lokasi yang sangat strategis untuk membangun sarana atau prasarana sosial, seperti gedung, sekolah, rumah sakit, pusat perbelanjaan, jalan raya, irigasi dan lain sebagainya. Tuntutan seperti ini menjadi motivasi untuk dilakukannya pemindahan makam ke lokasi lain.

2) Motivasi Pemindahan Mayat

d. Karena ada wasiat dari si mayat agar nantinya ia dikuburkan berdekatan dengan kuburan-kuburan keluarganya yang telah mendahuluinya. Tetapi, karena suatu hal ia dikuburkan jauh dari kuburan karib kerabatnya. Untuk merealisasikan wasiat tersebut, maka keluarga-keluarganya berupaya untuk memindahkan mayatnya atau tulang belulangnya ke tempat yang diwasiatkannya.

e. Adanya keinginan keluarga untuk menguburkan mayat di daerah asalnya, yaitu pemindahan mayat yang bukan merupakan wasiat, tetapi merupakan hasil kesepakatan keluarganya untuk mendekatkan kuburan si mayat dengan kuburan nenek moyangnya, untuk memudahkan menziarahinya.

3) Hukum Memindahkan Makam

Pada dasarnya memindahkan makam haram hukumnya kecuali kalau betul-betul dalam keadaan darurat, misalnya kalau makam itu selalu tergenang banjir atau tidak pernah lagi kering dan sebagainya. 
Menurut al-Suyuthi, ada lima macam alasan yang menjadi dasar pertimbangan dalam menempuh darurat, yaitu

a) Pertimbangan hajat yaitu kebutuhan yang sangat mendesak, sehingga manusia seharusnya mencari jalan keluar;

b) Pertimbangan manfaat yaitu upaya mencari manfaat meningkatkan taraf hidup manusia;

c) Pertimbangan keutamaan $(a l-F u d h u l)$ yaitu upaya untuk mencari sesuatu yang lebih utama agar mencapai tingkat kesejahteraan dan kebahagiaan hidup;

d) Pertimbangan ketertiban dan keindahan (al-Ziinah) yaitu upaya untuk menertibkan dan memberi nilai keindahan kepada sesuatu agar manusia selalu senang dan tenang;

e) Pertimbangan berhalangan atau (al-Tadzniib) yaitu menempuh dispensasi atau keringanan hukum karena mengalami suatu uzur. Dalam hal ini, dibolehkan selama uzur itu ada dan terlarang menilai tersebut telah hilang.

Dari penjelasan di atas, penulis menilai bahwa minimal ada empat pertimbangan yang cocok untuk dijadikan alasan pemindahan makam, yaitu:

a) Memindahkan makam dengan alasan untuk mendirikan rumah sakit. Pertimbangan seperti ini dapat dikategorikan pada pertimbangan hajat;

b) Memindahkan makam karena akan ditempati bangunan sekolah atau pusat perbelanjaan. Pertimbangan seperti ini dikategorikan kepada pertimbangan manfaat;

c) Memindahkan makam karena akan dibangun jalan raya atau sarana irigasi. Pertimbangan ini dapat dikategorikan kepada pertimbangan keutamaan (alfudhul);

d) Memindahkan makam dengan alasan akan dibangun tempat rekreasi atau sarana hiburan yang dihalalkan oleh agama. Pertimbangan ini dapat dikategorikan kepada pertimbangan keindahan (al-Ziinah).

Bila memindahkan makam dengan motivasi-motivasi di atas, maka tidak ada alasan untuk mengharamkannya, tetapi dibolehkan. 
4) Hukum Memindahkan Mayat

Adapun mengenai status hukum memindahkan mayat, maka dalam hal ini terjadi perbedaan pendapat di kalangan ulama. Ulama Malikiyah berpendapat bahwa dibolehkan memindahkan mayat baik sebelum dikuburkan ataupun setelah dikuburkan dengan syarat sebagai berikut ${ }^{21}$ :

a) Pemindahan mayat tersebut tidak akan menimbulkan kerusakan (dampak negatif) pada mayat tersebut;

b) Bahwa dengan pemindahan mayat tersebut tidak akan menimbulkan aib bagi mayat yang bersangkutan;

c) Pemindahan mayat tersebut bertujuan untuk kemaslahatan, seperti karena khawatirkan kuburan tersebut akan terkikis oleh air; pemindahan dengan alasan supaya lebih dekat dengan karib kerabatnya sehingga memudahkan mereka untuk berziarah dan lain-lain.

Jika syarat-syarat di atas tidak terpenuhi, maka diharamkan melakukan pemindahan mayat tersebut.

Menurut ulama Hanafiah, makruh hukumnya memindahkan mayat. Sebaliknya, disunatkan menguburkan mayat di mana ia meninggal. Bila belum dikuburkan, boleh dimakamkan di luar tempat meninggalnya, sepanjang jaraknya tidak melebihi dua mil. ${ }^{22}$

Menurut ulama-ulama Syafi'iyyah, haram hukumnya memindahkan mayat yang telah dikuburkan kecuali ke negeri Mekkah, Madinah dan Baitul Maqdis; walaupun telah diwasiatkannya. Oleh sebbab itu, di mana seseorang meninggal, maka di sanalah ia dikuburkan dan setelah itu tidak boleh memindahkannya ke tiga tempat di atas. ${ }^{23}$

Menurut ulama mazhab Hambali, disunatkan menguburkan orang yang mati syahid di tempat ia meninggal. Sedangkan menurut Imam Ahmad ibn

\footnotetext{
${ }^{21}$ Hasan Kamil al-Multhawi, Fiqh al-Ibadat 'ala Mazhab al-Imam Malik r.a, (Kairo: Maktabah al-Nahdhah al-Mishriyyah, tt), h. 216.

${ }^{22}$ Al-Mawardi, Al-Hawi Al-Kabir lil Fiqhil Imamis Syafi ‘i, h. 234.

${ }^{23}$ Al-Mawardi, Al-Hawi Al-Kabir lil Fiqhil Imamis Syafi ‘i, h. 238.
} 
Hambal, dibolehkan memindahkan mayat dari tempat matinya asalkan bukan karena mati syahid. ${ }^{24}$

Pengikut mazhab al-Auza'I dan Ibn Munzhir mengatakan bahwa tidak dibolehkan memindahkan mayat ke tempat yang lain, kecuali bila ada maksudmaksud tertentu.

Dari kontroversi dikalangan ulama di atas, penulis cenderung sependapat dengan ulama yang menyatakan bahwa haram hukumnya memindahkan mayat tanpa ada unsur kemaslahatan baik untuk mayat itu sendiri maupun untuk orang hidup. Sebaliknya, dibolehkan memindahkan mayat bila terdapat unsur maslahat, baik bagi mayat maupun bagi orang hidup. Karena orang hiduplah yang harus memperhatikan kemaslahatan mayat, namun tidak boleh menyulitkan orang hidup. Dengan demikian, seandainya orang hidup hal ini dibolehkan memindahkannya, asalkan tetap menjaga kehormatan mayat; misalnya

a) Tidak mengadakan pemindahan ketika diperkirakan mayat itu masih dalam proses pembusukan dikuburannya (belum hancur);

b) Diadakan pemindahan bila tinggal tulang-tulang yang belum termakan tanah. Maka tulang belulang itulah yang dipindahkan ketempat lain, lalu dikuburkan sebagaimana cara menguburkan mayat yang baru meninggal.

Dari dua kriteria di atas, maka dapat disimpulkan bahwa pembongkaran dan pemindahan makam hanya dapat dilakukan dalam kondisi darurat yang mengharuskan pembongkaran. Sementara perbedaan pilihan politik antara pemilik tanah atau pewakaf dan ahli kubur bukan alasan darurat yang mengharuskan pembongkaran dan pemindahan makam.

\section{Hukum Memindahkan Makam Sebab Beda Pandangan Politik}

Pembongkaran dan pemindahan makam tidak bisa dibenarkan hanya karena alasan perbedaan pilihan politik. Pembongkaran dan pemindahan makam hanya dapat dilakukan dalam situasi darurat seperti erosi sungai dan lain sebagainya.

$$
\text { وكذلك يحرم نقله بعد دفنه إلا لضورة }
$$

\footnotetext{
${ }^{24}$ Al-Mawardi, Al-Hawi Al-Kabir lil Fiqhil Imamis Syafi ‘ $i$, h. 241.
} 
Artinya:

Demikian juga haram memindahkan jenazah setelah dimakamkan kecuali dalam situasi darurat.

Imam Al-Mawardi menambahkan bahwa sebidang tanah makam yang sudah ditempati merupakan hak jenazah yang mengisi di dalamnya. Oleh karena itu, meski pemilik tanah awalnya hanya meminjamkan sebidang tanah untuk pemakaman, hak penempatan atas tanah tersebut menjadi milik jenazah yang menempati sebidang tanah tersebut.

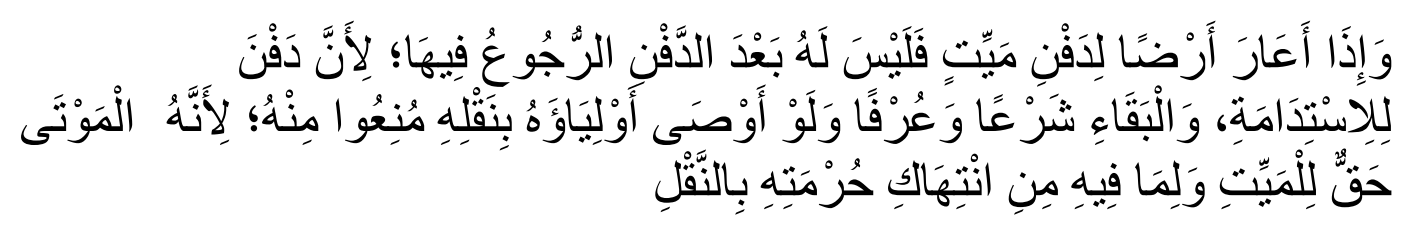

Artinya:

Bila seseorang meminjamkan sebidang tanah untuk pemakamam jenazah, maka ia tidak berhak menarik kembali tanahnya karena pemakaman jenazah itu bersifat langgeng dan kekal menurut syariat dan adat. Kalau seseorang mewasiatkan para walinya untuk memindahkan makam tersebut, maka mereka harus dilarang karena tanah itu merupakan hak jenazah dan pemindahannya dapat mencederai kehormatannya. ${ }^{25}$

Pelbagai keterangan ini, dapat menarik simpulan bahwa pembongkaran dan pemindahan makam hanya dapat dilakukan dalam kondisi darurat yang mengharuskan pembongkaran. Sementara perbedaan pilihan politik antara pemilik tanah atau pewakaf dan ahli kubur bukan alasan darurat yang mengharuskan pembongkaran dan pemindahan makam.

Penulis menyarankan semua pihak untuk memandang perbedaan pilihan politik sebagai perbedaan yang wajar dan fitrah. Perbedaan pilihan politik sebaiknya tidak perlu menjadi alasan perpecahan di tengah keluarga dan di tengah masyarakat. Kami menyarankan masing-masing pihak untuk menahan diri dari memaksakan kehendak terhadap pihak lain.

\footnotetext{
${ }^{25}$ Lihat al-Mawardi, Al-Hawi Al-Kabir lil Fiqhil Imamis Syafi ‘i, h. 241.
} 


\section{PENUTUP}

Pada dasarnya, membongkar kuburan haram hukumnya selama tulang mayatnya diduga masih ada di dalamnya. Namun ada beberapa motivasi (sebagaimana yang telah dijelaskan di atas) syara' yang membolehkan dilakukannya pembongkaran kuburan. Haram hukumnya memindahkan mayat tanpa ada unsur kemaslahatan, baik untuk mayat itu sendiri maupun orang hidup. Sebaliknya dibolehkan memindahkan mayat bila terdapat unsur maslahat, baik bagi mayat maupun bagi orang hidup. Pembongkaran dan pemindahan makam tidak bisa dibenarkan hanya karena alasan perbedaan pilihan politik antara pemilik tanah atau pewakaf dan ahli kubur karena bukan alasan darurat yang mengharuskan pembongkaran dan pemindahan makam. 


\section{DAFTAR PUSTAKA}

Bani, M. Nashiruddin al-,Menyelenggarakan Jenazah: Antara Sunnah dan Bid'ah, Pent. S. Ziyad Abbas, Jakarta: Pustaka Panji Mas, 1991.

Bashri, Abi al-Hasan Ali Ibn Muhammad ibn Habib al-Mawardi al-, aal-Hawi alKabir, J. 3, Beirut: Dar al-Kutub al-'Ilmiyyah, 1994.

Dahlan, Abdul Aziz (et.al), Eksiklopedi Hukum Islam, Jakarta: Ichtiar Baru van Hoeve, 1997.

Jardani, Muhammad Abdullah al-, Fath al-Alam bi Syar Mursyid al-Anam, j.3, Kairo Dar al-Salam, 1990.

Jaziri, Abdul Rahman al-, Fiqh Empat Mazhab, Pent. Chatibul Umam dan Abu Hurairah, Jakarta: Darul Ulum Press, 1996.

Mahyuddin, Masailul Fiqhiyyah, Jakarta: Kalam Mulia, 1998.

al-Mawardi, Al-Hawi Al-Kabir lil Fiqhil Imamis Syafi 'i. Beirut, Darul Kutub AlIlmiyyah: 1994 M-1414 H.

Mughniyyah, Muhammad Jawad, Fiqh Lima Mazhab, j. 1, pent. Team Basrie Press, Jakarta: Basrie Press, 1991.

Multhwi, Hasan Kamil al-, Fiqh al-'Ibadat 'ala Mazhab al-Imam Malik r.a., Kairo: Maktabah al-Nahdhah al-Mishriyyah, tt.

Nawawi, Abi Zakariya Yahya ibn Syaraf al-, al-Majmu'Syar al-Muhazzab, j. 5, Beirut: Dar al-Fikr, 1972.

Raudhah al-Thalibin, j. 1, Beirut: Dar al-Kutub al'Ilmiyyah, tt.

Qudamah, ibn, al-Mugni 'ala Mukhtasar al-Khurafi, j. 2., Beirut: Dar al-Kutub al'Ilmiyyah, tt.

Ritonga, A. Rahman dan Zainuddin, Fiqh Ibadah, Jakarta: Gaya Media Pratama, 1997.

Rusyd, Ibn. Bidayah al-Mujtahid,j. 1., Beirut: Dar al-Fikr, tt.

Shiddiqy, T.M. Hasbi ash-, Koleksi Hadis-hadis Hukum, j. 6, Jakarta: Yayasan T.M. Hasbi ash-Shiddiqy, 1994.

Suyuthi, Jalaluddin al-, al-Asybah wa al-Nazhair fi al-Furu', Beirut: Dar al-Kutub al-Ilmiyyah, 1979.

Syaukani, al- Nail al-Author, j. IV, Mesir: Musthafa al-Babi al-Halabi, tt. 